\title{
A DISCIPLINA ENFERMAGEM MATERNO-INFANTIL NUM PROGRAMA DE ASSISTENCIA INTEGRADA - "ENSINO, PESQUISA E ESTENSÃO. *
}

\author{
** Rosalda Cruz N. Paim \\ ** Irene S. Gallindo \\ ** Alides de S.Pinto \\ *** Edila Pinheiro Pinto \\ *** Solange Lourdes de S. Chaves
}

RBEn/01

PAIM, R.C.N. e colaboradoras - A disciplina enfermagem materno-infantil num programa de assistência integrada - "ensino, pesquisa e extensāo. Rev. Bras. Enf.; DF, 31 : 417-442, 1978.

\section{EXPERIENCIA ANTERIOR}

\section{O Probelma em si:}

Constitui este estudo o resultado ainda em fase embrionária do desenvolvimento da programação de atividades docente-assistenciais realizadas no Núcleo de Orientação à Saúde "N.O.S." Materno-Infantil sob a orientação da disciplina Enfermagem Materno-Infantil.

Face a necessidade de planejamento, controle e avaliação de atividades que seriam executadas, inicialmente esta. beleceu-se contatos com a Chefia do setor de internação e alta e com a coordenação do Projeto Integrado Saúde Materno Infantil "P.I.S. M.I." e subdire- toria do serviço de Enfermagem do Hospital Universitário Antônio Pedro, todos os órgãos referidos passaram a colaborar direta ou indiretamente para o êxito do processo de implantação.

A iniciativa representa a aplicação de uma metodologia Científica de Enfermagem, de nossa autoria, constante de tese de Livre Docente, cuja abordagem sistêmica é uma constante no curso de todas as fases do trabalho, desde o diagnóstico e programação para atingir as etapas de intervenção, avaliação e reajustes, contribuindo assim para maior produção e melhores resultados através de pessoas (equipe) motivando e utilizando as potencialidade de cada uma.

* Trabalho apresentado no XXX CBEn - Belém - Pará.

** Professores da Universidade Federal Fluminense.

*** Enfermeira e Professoras Colaboradoras da UFE. 
PAIM, R.C.N. e colaboradoras - A disciplina enfermagem materno-infantil num programa de assisténcia integrada - 'ensino, pesquisa e extensão. Rev. Bras. Enf.; DF, 31 : 417-442, 1978.

Buscamos ainda, a nível operacional, integrar as demais disciplinas da área Materno-Infantil e serviço de Internação e Alta, mediante atividades nos diversos ambulatórios e Unidade Móvel, que passou a operar em comunidades cobertas pelo Hospital Universitário Antônio Pedro.

Apresentamos uma análise e um conjunto de proposiçōes, com base no reflexo de atividades docente-assistencial em campo clínico, com ações dirigidas, de forma integrada, articuladamente com os diversos departamentos envolvidos no P.I.S.M.I. e deste com a Secretaria Municipal de Saúde de Niterói.

Tais atividàies visam não só assegurar um melhor padrão de ensino de Enfermagem e permitir a qualificação da assistência em tela, através de operacjonalização nos diversos níveis de prevenção de I.eavell \& Clark. Promoção da Saúde, proteção específica, diagnóstico e tratamento precoce, limitação do danc e reabilitação, abrangendo os períodos pré-concepcional, concepcional e pósconcepcional e a nivel individual, familiar e comunitário.

\section{Justificativas:}

A par da necessidade de se implantar um campo ciínico adequado às açōes docentes, é importante considerar o atendimento ao grupo Materno-Infantil que apresenta condiçōes peculiares biopsicossociais, clientela prioritária, do Plano Nacional de Saúde representa çarcela ponderável da população brasileira $(70 \%$; a mais vulnerável aos riscos de inorbimortalidade Materno-Infantil.

O município de Niterói apresenta uma população estimada de: 397.900 habitantes (ano de 1977). com cerca de $35 \%$ de população favelada e $65 \%$ da população urbana num total de 66.452 domicilios. As condiçōes de moradia e de sanea- mento básico são bastante carentes, condicionantes das altas taxas de morbimortalidade para o grupo MaternoInfantil, similares aos do país.

Em que pesam as deficiências do sistema de informaçōes, os dados disponíveis evidenciam que as crianças de $\mathrm{Ni}$ terói, em sua maioria adoecem e morrem por causas totalmente preveniveis.

Dentro desta realidade, encontra-se o HUAP, prestador de serviços para uma clientela muito grande, hospital docentc, que recebe e trata, no entanto, todo tipo de problemas de saúde de uma ampla área de influência.

Em relação as áreas comunitárias: Vila Ipyranga, Ilha da Conceição e Pendotiba, funcionam no sistema de derivação e referência a nível periférico, para realizar após avaliação correspondente uma maior extensão operacional, integrado ao programa da Secretaria Municipal de Saúde estendendo-se a outros postos.

A implementação deste projeto além de facilitar as açōes docentes, virja permitir uma reformulação de objetivos e política de atenção Materno-Infantil, visando regionalização e aglutinação de vários sub-projetos de "Dinamização dos Ambulatórios" (pré-natal, puericultura e pediatria), sub-projetos "Qualificação de Assistência aos pacientes Internados), sob a gerência ou responsabilidade de Enfermagem, o que permitiria um programa globalístico e mais integrado, com açōes programáticas dirigidas as prioridades de cada setor do grupo em causa. atendendo em extensão até a unidade volante. Desta forma se buscou melhores estratégias para se tornar realizável os objetivos do hospital moderno mormente em se tratando de um hospital universitário.

A deficiência de sistematização nas ações assistenciais, bem como a fragmentação de ações de Saúde evidenciadas, constituem obstáculo a otimização 
PAMM, R.C.N. e colaboradoras - A disciplina enfermagem materno-infantil num programa de assistência integrada - "ensino, pesquisa e extensąo. Rev. Bras. Enf.; DF, 31 : 417-442, 1978.

do processo assistencial, além de refletir no comportamento do estudante, que geralmente percebe tal descontinuidade e/ou ausência de determinadas açōes, resıltando numa deformaçāo do perfil do futuro profissional. Isto porque os ambulatórios Materno-Infantil nāo tinham estrutura e meios de funcionamento de forma integral se refletindo no ensino e na assistência moderna, o que justifica em parte o fluxo de paciente do modo como se vinha observando.

Como militante dó ensino e membro integrante do "P.I.S.M.I." mesmo através de uma avaliaçāo parcial, com bases em observaçōes empíricas e algumas pesquisas realizadas na área em questāo pode-se evidenciar um nível assistencial insatisfatório expresso por:

- grande reincidência de internaçōes sobretudo em conseqüência a danos evitáveis pelos meios usuais de que dispomos.

- evasāo dos pacientes materno-infantis dos ambulatórios.

- grande afluência de casos de atendimentos de emergência, que na realidade nāo constituem emergência.

- não ágendamento, para retorno ambulatorial e grande número de faltoscs na puericultura e pré-natal, com riscos para esta clientela.

- A descontinuidade assistencial dos pacientes em tratamento ambulatorial ou pós internação, que passam a ser atendidos nos corredores das clinicas do HUAP.

- A dificuldade de regionalização e o afastamento dos reais objetivos de um hospital de grande porte como 0 HUAP.

- $\mathrm{O}$ aumento de números de pacientes que por falta de uma sistemática de trabalho e documentação trazem prejuízos ao hospital.

- A discrepância numérica existente entre a clientela que freqüenta a puericultura e a pediatria, assim como o número de pacientes que fazem pré-natal e aqueles que dão entrada na maternidade do HUAP, sem assistência pré-natal.

- Baixo nível de informaçāo de saúde, da clientela em questão.

Como fatores condicionantes da problemática em tela, observa-se ainda:

- Inadequada estrutura organizacional e da planta física.

- Falta de unidade de orientação à saúde, criando dispersāo e má canalização dos esforços do grupo.

- Deficiência da dinâmica funcional na área Materno-Infantil, ocasionado em parte por desconhecimento de alguns profisisonais de seus verdadeiros papéis e/ou modo de agir dentro de um "MODELO SISTEMICO".

E evidente, que tal situaçāo decorra da ausência de um planejamento global, no qual se considera os postulados de-finidos pela política Nacional de Saúde, e legislação vigente (Lei 6.229) do Sistema Nacional de Saúde, em consonância com a "O.M.S.".

Obviamente a preparação de recursos humanos para o setor de Saude, deve estar coerente com a Politica Assistencial adotada, cujos profissionais, ao final do processo ensino-aprendizagem deverāo ter a performance adequada, àquele correspondente às necessidades do aparelho utilizador. Reconhece-se que além da inexistência de implantação e implementaçāo "N.O.S." "MaternoInfantil"; onde a triagem, agendamento, e nucleamento de Orientação à Sa úde, se estabelece sistematizadamente, há falhas de integração e dispersāo de esforços dos profissionais atuantes na referida área.

Fara melhor compreensāo da estrutura e dinâmica da programaçāo em causa apresentamos os diagramas ilustrativos (vide Fig. 1, 2, 3, 4, 5). 
PAMM, R.C.N. e colaboradoras - A disciplina enfermagem materno-infantil num programa de assistência integrada - "ensino, pesquisa e extensāo. Rev. Bras. Enf.; DF'. 31 : 417-442, 1978.

Nas metas propostas em projeto pretende-se :

- Oferecer um MODELO INOVADOR na área Materno-Infantil como marco referencial de ação integrada nos seus diferentes níveis. (anexo 2).

- Dinamizar o atendimento assistencial da faixa ambulatorial: pré-natal, puericultura e pediatria em consonância com as metas do "P.I.S.M.I" (Projeto Integrado Saúde Materno Infantil), possibilitando a cobertura de $60 \%$ da clientela em termos de proteção específica através da consulta de enfermagem, promoçāo da saúde.

Em nosso estudo como objetivo geral pretende-se proporcionar os meios adequados ao processo ensino-aprendizagem em campo clínico de modo a:

- Permitir uma performance do profissional compativel às reais funçōes que irá desempenhar.

- Otimizar a assistência a ser prestada à clientela em seu aspecto biopsicossocial na tentativa de elevar o padrāo assistencial da população prioritária, consoante à Politica Nacional de Sa úde e do ensino de Enfermagem Materno Infantil.

- Desenvolver programas de extensāo e participar atividades de integraçāo docente-assistenciais e de pesquisas, visando, despertar na equipe multiprofissional o espírito de investigaçāo.

- Dotar o Núcleo de Orientação à Saúde "N.O.S." de uma estrutura organizacional, capaz de permitir o maior grau de racionalizaçāo do modelo operacional de integraçāo entre o subsistema ensino, aparelho formado de recursos humanos e HUAP

- o subsistema prestador de serviços de Saúde na faixa ambulatorial Materno-Infantil.

\section{METODOLOGIA:}

Para diretrizes desta programaçāo partiu-se da implantaçāo e implementaçāo da "N.O.S." Materno Infantil ora criada como $10^{\circ}$ apoio mediante:

- Perfeita integração com as dema is disciplinas.

- estreitamento das relaçōes docentesassistenciais, individual, coletiva, paciente equipe e equipe entre si.

- interação coerente de todo sistema hospitalar "HUAP", intra e extra muro.

- informaçāo, discussāo e análise de normas e critérios de atuaçāo para uma definiçāo e reformulaçāo das linhas de açāo programáticas em adequaçāo a nova realidade nos diversos niveis de promoçāo, proteção e recuperaçāo da saúde.

Fundamentou-se o projeto em duas fases sequenciais: Investigaçāo diagnóstica (exploratória) e operativa (sistematização de açōes ou de aplicação).

O estudo piloto com pessoal de nível universitário operante na área, visou obter uma média das opiniōes a respeito do problema, capaz de orientar a formulaçāo de hipóteses e facilitar a seleçāo de instrumentos adequados a coleta de dados.

\section{Critêrios de Derivação:}

- Para os Municípios em comunidades com postos já implantados:

- Centro comunitário de Fonseca (C.C.F.), Ilha da Conceição e Pendotiba.

\section{Encaminhamentos:}

- Recém-nato após BCG intradérmico e avaliação pela equipe multi-profissional (com 2 a 3 concentraçōes de consultas, sendo duas por enfermeiros e 
PAIM, R.C.N. e colaboradoras - A disciplina enfermagem materno-infantil num programa de assistência integrada - "ensino, pesquisa e extensåo. Rev. Bras. Eñf.; DF, 31 : 417-442, 1978.

uma consulta médica para cada criança), abrangendo 40 a 45 dias, até a alta.

- Puérpera após decorrido pós-natal e preventivo do cancer.

- Lactentes, pré-escolares e escolares que tenham no município a equipe de saúde que assuma (crianças sadias e/ou portadoras de sífilis).

- Vigilância epidemiológica, de casos, para seguimento pós alta.

- Criança doente, dependente de atenção pediátrica básica (não consideradas de médio e alto risco), seguimento de casos em domicílio.

- Dos Municipios para o HUAP - cuja referência é o "N.O.S.". Serão encaminhados:

- Situações de alto risco e médio risco (casos de controle e tratamento).

- Internação de alto risco e ausência de recursos da comunidade para 0 atendimento.

- Áreas de ação e prioridades (vide Figura 4).

\section{Sistema de Referência:}

Dados estatísticos preliminares do "P.I.S.M.I." e pesquisa efetuadas na área nos periodos iniciais de investigação diagnóstica, estudo piloto, representando um diagnóstico de situação que serviriam como antecedente do problema.

Durante o estudo adotamos a seguinte metodologia (fases metodológicas) :

$$
\begin{aligned}
& 1 \text { - Investigação Diagnóstica } \\
& \text { s - Planejamento } \\
& \text { a - Implementação } \\
& 4 \text { - Avaliação }
\end{aligned}
$$

Avaliação do resultado tas açõ :s desenvolvidas, de forma contínua e periodicidade pré-estabelecida, poss!bilitando "Feed-Back" para a continuidade do processo de planejamento e maıtutenção dos resultados obtidos, segundo procedimento em linha docente assistencial, multiprofissicnal e interdisciplina: e áreas de ação programática.

\section{5 - Reajustes}

Após avaliação contínua da equipe, vem sendo, introduzido o reajuste no sistema, que permite a retroalimentação para as açōes de ensino como para a assistência Materno Infantil, com base nas articulaçōes e reuniōes mantidas pela coordenação. "R.I.D.A."

- Ação da equipe "MENSO" (Medicina, Enfermagem, Nutrição, Serviço Social e outros).

Sujeitos e procedimentos:

$\mathrm{Na}$ fase de investigação diagnóstica usou-se como instrumento: entrevistas, questionários e observação.

$\mathrm{Na}$ fase de aplicação

Os instrumentos (fichas, documentários, formulários e outros) serviram para orientação ao estudo dos informes colhidos em documentos elaborados especialmente para este fim (anexo) e os utilizados nos setores de atuação como ficha única e outros.

Trata-se pois de pesquisa descritiva da avaliação de açōes, que resultaram na produtividade atingida (quadros: IV e V), par da aceitação da equipe e cobertura de extensão rápida dos trabalhos, conforme sua evidência no desenvolvimento do estudo. além do mais um projeto integrado "Ensino, Assistência e Extensão", incluindo por essa razão na programação da "COEX" da Universidade Federal Fluminense.

\section{OPERACIONALIZAÇAO:}

As diretrizes programáticas de ação com sentido de continuidade e integração docente assistencial propostas, devem ser entre outras promovidas, através ativiclades de: 
PAIM, R.C.N. e colaboradoras - A disciplina enfermagem materno-infantil num programa de assistência integrada - "ensino, pesquisa e extenš́o. Rev. Bras. Enf.; DF, 31 : 417-442, 1978.

1 - ENSINO: treinamento de graduandos, internos e residentes da área de saúde, treinamento de pessoal auxilliar (aux. enf. e aux. de saúde).

2 - PESQUISA: na linha de pesquisa dez (10) subprojetos estão em estudos já iniciados.

3 - EXTENSAO: comprovadas por atividades, conforme quadros de atividades do $1 .^{\circ}$ trimestre referidos no estudo (quadro IV, V).

4 - INDICADOR DE MUDANÇAS E CRITERIOS:

- Coordenaçāo, execuçāo e avaliação das pesquisas, em andamento.

- Alcance das metas e objetivos previstos.

- Concentração das consultas de Enfermagem e médicas.

- Número de imunizaçōes e matrículas e fe tivadas.

- Diminuiçāo dos índices de mortalidade e reinternaçōes e problemas com o recém nato.

- Número de pacientes que retornam ao pré-natal, pós-natal e preventivo do câncer.

- Freqüência de casos de aleitamento materno.

- Freqüência às aulas no "G.O.S." (Grupo de Orientaçāo a Saúde); prégestante, pré-termos e mais tratamentos efetivados.

- Redução da frequiência a emergência pediátrica por situaçōes que nāo sāo de emergência.

- Modificação comportamental (valores e atitudes) da gestante e do pai.

- Aumento de pondo estatural das crianças.

- Partícipação dos profissionais nas reuniōes e execuçāo dos programas.

- Visita domiciliar e segmento dos casos.

- Retorno dos pacientes para consulta.
PLANO DE ATIVIDADES: (com base nOS OBJETIVOS ESPECIFICOS)

Núcleo de Orientação à Saúde Materno Infantil.

Efetivar o seguimento de casos (ambulatoría! e de internaçāo pós-alta), através de: TRIAGEM, CONTROLE, AGENDAMENTO, NUCLEAMENTO E VISITA DOMICILIAR.

- Sistematizar a assistência Materno Infantil, na faixa ambulatorial.

- Realizar interação nos vários níveis de complexidade e participaçāo crmunitária, mediante estabelecimento de mecanismos de integraçāo e tentativa de regionalizaçāo assistencial, assegurando a derivação segundo normas dos casos obstétricos e pediátricos, diagnosticados como médio e alto risco.

- Realizar investigação diagnóstica da clientela (projeto de Pesquisa) e terapêutica indicada (Operacionalizaçāo) para um crescimento social do grups Materno Infantil.

- Otimizar as AÇOES DE SAÚDE, a través consultas de Enfermagem e Educação para a Saúde no "N.O.S." Materno Infantil, na tentativa a conscientizaçāo para busca de melhores padrōes te vida, minorar os esforços e maximizar os resultados de modo eficiente $e$ ricaz.

- Propiciar os meios de diagnóstico, controle, tratamen to de forma contínua e precoce, e avaliaçāo do grupo Materuo Infantii de maior risco, através coleta, registros de dados e complementariedade de açōes Interprofissionais: PROJETOS DE PESQUISA.

Aumentar para $60 \%$ a cobertura do campo Materno Infantil na atençāo primária em consultas de enfermagem e atividades de extensāo na unidade móvel como o $1 .^{\circ}$ apoio disciplina de enfermagem Materno Infantil (estatística).

- Permitir os meios de: 
PAIM, R.C.N. e colaboradoras - A disciplina enfermagem materno-infantil num programa de assistência integrada - "ensino, pesquisa e extensão. Rev. Bras. Enf.; DF, $31: 417-442$, 1978.

Atuaçāo integrada e em vários níveis (modelo proposto figura 3) adotando procedimentos normais e resultados operacionais necessários ao aumento da efícácia.

Educaçāo contínua do pessoal auxiliar de enfermagem (HUAP) e agente de saúde do município de Niterói.

- Efetivaçāo de orientaçāo dídática pedagógica, de educaçāo para a saúde, para graduados de enfermagem internos e residentes da área de saúde Materno Infantil (programa aprovado no PISMI).

Operacionalizaçāo específica a Nível: individual, familiar e comunitária.

- Complementar a atenção médica no mínimo de 4.500 gestantes e 6.000 crianças ao ano, com atividade de enfermagem pré e pós consulta, consulta de enfermagem $e$ orientação à saúde do núcleo familiar, sobre doenças prevalentes e dos alunos de alto risco: diarréia, desnutriçāo, doenças transmissiveis, prétermos e outros riscos materno infantil.

- Apresentação gráfica e estatística das atividades do serviço de enfermagem.

- G.O.S. (Grupo de Orientação a Saúde) para gestantes, pretermos, puerperas e māes de crianças internadas.

- Identificar a posição de enfermagem nas atividades da assistência materno infantil, visando caracterizar as reais funçōes do enfermeiro nos programas de saúde e conservaçāo do crescimento profissional dentro da equipe.

- Prescriçōes de enfermagem e execuçāo de cuidados complexos de atenção primária, exame físico e evoluçāo de enfermagem.

- Prestar assessoria de enfermagem em assuntos de saúde materno infantil.

- Reuniāo e avaliaçāo da equipe de Sa úde "R.I.D.A".

\section{NO AMBULATÓRIO PRE-NATAL}

Com base no projeto "Dinamizaçāo do ambulatório pré-natal", pretende-se ao final de um ano qualificar e aumentar a cobertura de $60 \%$, a clientela "Gestante" através de:

- Realização do controle de Saúde da gestante que freqüenta o HUAP com necessidades de atenção primária, secundária ou terciária.

- Prevenção das intercorrências gestacionais e complicaçōes do parto e puerpério, a partir do diagnóstico de necessidades e detectaçāo de situaçōes de Riscos que atingem a mulher e o concepto.

- Supervisāo e orientação adequada da puérpera, visando pós-natal prevençāo de doenças ginecológicas e prevenção do câncer.

- Realizaçāo de orientaçāo à saude a nivel individual "Consultas de Enfermagem" e grupais "G.O.S." (primiparas e de risco), a fim de permitir a maximização dos efeitos positivos de uma gestação sadia e nascimento de uma criança normal e a termo.

\section{AMBULATORIO DE PUERICULTURA}

A equipe deve permitir os melos de:

- Reduzir de $60 \%$ a incidência de doenças erradicáveis pela imunizaçāo ou promoçāo da saúde e proteçāo específica.

- Estabelecer o controle de saúde infantil e realizar a educaçāo para a saúde a nível individual e grupal "G.O.S." permitindo a mudança comportamental, em relação ao baixo nível de informaçāo, conduta inadequada sobre problema de saúde.

- fazer cobertura de $70 \%$ dos lactentes do HUAP, com açōes de atenção pediátrica básica fixando como norma a concentraçāo de 7 consultas, mínimas para o recém-nato normal e 18 para os pré-termos e de alto risco no primeiro ano de vida. 
PAIM, R.C.N. e colaboradoras - A disciplina enfermagem materno-infantil num programa de assistência integrada - "ensino, pesquisa e extensão. Rev. Bras. Enf.; DF, 31 : 417-442, 1978.

- aumentar de 70\% o índice de aleitação materna para os lactentes até o terceiro mês.

\section{NO AMBULATÓRIO DE PEDIATRIA}

- reduzir a morbimortalidade infantil da criança matriculada no ambulatório em $50 \%$ dos casos de desnutrição e outros danos erradicáveis por promoção de saúde e proteção específica.

Permitir os meios de:

- Vigilância epidemiológica, controle de comunicantes (casos de Doenças Infeçıo Parasitárias).

- Assegurar diagnóstico precoce e tratamento eficaz e oportuno.

- Reduzir o índice de reinternação por situaçōes patológicas preveníveis através da Educação para Saúde e Imunização.

- Seguimento e retorno ambulatorial, através PLANO de ALTA e VISITA domiciliar dos casos de evasão (Sub projeto).

- Manter sob controle e derivação à Comunidade, segundo a maior complexidade $80 \%$ de casos que constituem prioridade do programa.

\section{NA EMERGENCIA PEDIATRICA}

Permitir a população que freqüenta a emergência pediátrica os meios de:

- valorizar a necessidade de matrícula da criança para o seguimento de tratamento e continuidade ambulatorial (encaminhamento à matrícula), através educação para saúde (orientação à ALTA).

\section{NO POSTO DE IMUNIZAÇAO}

- Espera-se dinamizar e atingir uma cobertura de $70 \%$ visando:

- prevenir as doenças controláveis por imunização seguindo rotina bai- xada pelo Ministério da Saúde e normas de vacinação do Estado do Rio.

- contribuir para consecução das metas do governo, através de participação nas Campanhas de vacinação.

\section{ANALISE E INTERPRETAÇAO DOS RESULTADOS}

A dificuldade precípua na descrição do trabalho realizado é decorrência do seu caráter multifacial, abrangente, aparentemente dispersivo na resultante de uma ação proposital, objetivando a integração dos aspectos, enfocados através de uma visão generalística, fato que, paradoxalmente, individualiza este esforço.

Desenvolvido o estudo a partir de algumas hipóteses que só serão evidenciadas e testadas as conclusōes no final do projeto em causa, já podemos afirmar:

- Da viabilidade deste tipo de atividade na rotina do ambulatório com reflexo positivo na clientela Materno-Infantil.

- Da necessidade de se partir para assistência ao paciente com ênfase na, enfoque SAUDE em linha de Extensão e com participação da Comunidade.

- Da necessidade que se execute na prática o que a lei do Sistema Nacional de Saúde determina, a partir de uma abordagem sistêmica.

As ativiciades docente-assistenciais definidas estão sendo desenvolvidas no HUAP e em áreas geográficas selecionadas no Município de Niterói, através regionalização e hierarquização de ações. (Fig. 1 e 2).

No HUAP ao lado do ensino, desenvolve-se um trabalho de consolidação dos serviços de obstetrícia, puericultura e pediatria em faixa ambulatorial em integração com o Serviço de Internação e Alta, a fim de posicionar progressivamente a Instituição ao seu papel de hospital docente-assistencial de grande complexidade, de referência e derivação 
PAIM, R.C.N. e colaboradoras - A disciplina enfermagem materno-infantil num programa de assisténcia integrada - "ensino, pesquisa e extensåo. Rev. Bras. En?.; DF, 31 : 417-442, 1978.

para área. Da mesma forma mantém-se conconitantemente realização de atividades de prevenção, promoção e atenção pediátrica, obstétricas básicas para a população que demanda espontaneamente.

Na mecânica operativa da comunidade, as atividades básicas de atenção materno-infantil se desenvolvem com critérios de atividades normatizadas e regionalizadas, com a presença da equipe de saúde local, mediante documento oficializados as partes (HUAP e comunidade) assumem compromissos perante a clientela atendida. Integra-se nesta equ:pe o auxiliar de saúde, elemento treinado da própria comunidade, nexo entre a mesma e o sistema de saúde, assumindo portanto um papel de particular relevância.

Em relação a um dos subprojetos sobre desnutridos internados, os dados nos mostram:

Dos 309 pacientes, 192 (62\%) eram desnutridos de diversos graus (D1, D2 e D3), apesar de sua primeira causa de internação, não ter sido desnutrição e destes 56 casos, tratava-se de D.P.C. de 3.' grau.

Desses observa-se 62 casos (22\%) total de obtuário por desnutrição. Dos 20 casos de D3 as causas mortes foram: pneumonia, septicemia e distúrbios metabólicos, acrescendo que esses pacientes tiveram seu desmame precoce.

Dos fenômenos sociais detectados pela equipe no núcleo familiar, mostra-nos o seguinte a situação nível familla:

$53 \%$ (mães solteiras); $18 \%$ (desintegração familiar) $73 \%$ (família llegalmente constituída) e $17 \%$ (família numerosa).

Quanto zo nível Educação, $80 \%$ evidenciava baixo nível de educação para Saúde e em relação à renda familia $\mathbf{7 0 \%}$ percebia 1/2 salário mínimo apenas.

Ainda com brse na Diagnose Avaliativa evidenciada nos "G.O.S." (gestan- tes e puerperio) $83 \%$ apresentavam balxo indice de informação sobre problemas de saúde.

\section{RESULTADOS DE AVALIAÇAO DOS ALUNOS}

Pela dinâmica do Ensino, desde a $1 .^{\mathrm{a}}$ semana, eles têm \& oportunidade de assumir, observar e realizar fichamentos de conteúdos necessários à assistência ao paciente, além de receber orientação apurada sobre a maneira de como deverá atuar.

Percebe-se a aceitação da equipe em relação ao aluno e ao trabalho do "N.O.S." e o espírito de colaboração por parte de toda a equipe. Enfermeiros e médicos passavam mesmo a reclamar a presença do estudante quando um setor ainda não havia constituído a assistência de sua jurisdição, como foi o caso co preventivo do câncer e da Puericultura.

Simultaneamente, introduziu-se modificaçōes para o Ensino na Disciplina de Enfermagem Materno-Infantil, aproveitando as últimas aquisiçōes da pedagogia atual, correlacionadas com a educação para a Srúde. Este aspecto visa proporcionar um tipo de aprendizagem a partir de regras de proteção à saúde, ao começar pelo próprio aluno quando ingressa na área, o qual se submete a exames clínicos e laboratoriais. $O$ aluno tem também a oportunidade de assumir funçōes de liderança a clientela e solecionar problemas além de permitir o desenvolvimento do processo de Enfermagem (planejada) a partir da educaçāo para saúde.

Outro aspecto, que bem pode ser evidenciado é o interesse e produtividade no campo clínico além de depoimentos dos estudantes, comprovados por entrevistas e questionários de avaliação, com reflexos positivos. 
PAM, R.C.N. e colaboradoras - A disciplina enfermagem materno-infantil num programa de assistência integrada - "ensino, pesquisa e extensão. Rev. Bras. Enf.; DF, 31 : 417-442, 1978.

A partir disto o "N.O.S." que não dispōe ainda de pessoal qualificado para atuar no período de carência de alunos (2 meses de férias e verificação suplementar) de 20/6/1978 a 3/8/1978, 95\% dos estudantes se listaram como voluntários no programa, além de alguns profissionais (enfermeiros e professores), que se colocaram a disposição do trabalho.

A avaliação de resultados da implantação do "N.O.S.", com consultas de enfermagem no que se refere à pacientes integrante dos grupos experimental e de controle, são evidenciados na tabela a seguir:

\section{ELEMENTOS INFORMATIVOS}

1. Alimentação materna

2. Puerpério com problema

3. Cóto umbilical com problemas

4. Registro do R.N.

5. Controle ambulatorial

6. R.N. com problemas

7. Não vacinadas

8. Problema higiênico

$\begin{array}{rr}34 & \mathbf{3 8 \%} \\ 9 & \mathbf{1 8 \%} \\ & \\ 2 & 4 \% \\ 35 & \mathbf{7 0 \%} \\ 41 & 82 \% \\ 7 & 14 \% \\ 6 & 12 \% \\ 8 & 16 \%\end{array}$

1. Alimentação materna

$20 \quad 40 \%$

2. Puerpério com problemas

3. Côto umbilical com problemas

$8 \quad 16 \%$

4. Registro do R.N.

5. Controle ambulatorial

6. R.N. com problemas

7. Não vacinadas

8. Problema higiênico

$1530 \%$

$2142 \%$

$2154 \%$

$4692 \%$

$46 \quad 92 \%$

FONTE: Ficha, histórico e evolução de enfermagem.

$\begin{array}{llll} & + & - & \text { Total } \\ \text { Controle } & 20(27) & 30(23) & 50 \\ \text { Experimental } & 34(27) & 16(23) & 50 \\ \text { Total } & 54 & 46 & 100 \mathrm{X}^{2}=7,88 * *\end{array}$

* Significativo ao nível de $1 \%$ de probabilidade: Item 2 - não significativo e item 3 - significativo a $5 \%$.

Os itens 4, 5, 6 e 7 - Significativos ao nível de $1 \%$.

Observou-se que o retorno 20 ambulatório e à consulta de enfermagem cresceram muito em conseqüência deste trabalho, além do aumento de participaçào nas aulas promovidas, murais apresentados, e a validade das visitas domiciliares, nos seguimentos de casos.
As $1 .^{\text {a }}$ consultas são feitas pela enfermagem, visando a elaboração do histórico e triagem e os registros lançados na ficha única. Disto resulta também:

- Entrosamento com os médicos para triagem das crianças (sadias e doentes) através consultas de enfermagem. 
PAIM, R.C.N. e colaboradoras - A disciplina enfermagem materno-infantil num programa de assisténcia integrada - "ensino, pesquisa e extensão. Rev. Bras. Enf.; DF, 31 : 417-442, 1978.

- Encaminhamento para exames e tratamentos de pacientes com outros problemas (sifilis) verminoses, toxoplasmose, etc. e de caráter econômico-social, aos devidos setores, a fim de avaliar o crescimento infantil, orientar a alimentação, prevenção de acidentes e doenças e promover imunizaçōes. Incentivase também a efetuação de registros civis em alguns casos o próprio Serviço Social realiza este registro gratuitamente, através dos canais competentes.

Nas consultas de enfermagem (PréNatal e Puericultura) "serão marcadas as datas de consultas médicas, segundo critérios de concentração, exceto nos casos patológicos. A cargo da enfermeira estão as nalestras de Orientação à Saúde, ministração de cursos psico-profiláticos e a avaliação das necessidades biopsicosociais da gestante encaminhando. se ao Serviço Social ou Nutrição nos casos indicados. Mediante 0 exercício de todas as funçōes que atualmente são atribuídas ao enfermeiro suprime-se consultas médicas desnecessárias, por ser de atenção de saúde, aumentando consequentemente a cobertura a esta comunidade;

- da consciência desse objetivo estabelece-se uma perfeita harmonia não só de filusofia de trabalho, mais também no próprio relacionamento interpessoal de todos os componentes da equipe hospitalar (administração, médicos, enfermeiras, assistentes sociais e nutricionistas);

- as consultas de enfermagem são realizadas desde 0 primeiro comparecimento, quando a matrícula ainda é obr:gatória e canalizada para os postos de Imunização ou de Puericultura, após o que se orienta para a matricula, visando os atendimentos futuros.

Considerando-se que o ensino é a atividade precípua dos promotores deste trabalho, representando o hospital e a comunidade o seu campo de ação, a for- mação profissional de enfermagem é seu produto final - principal preocupação, buscando sempre proporcionar ao acadêmico de enfermagem e outros profissionais da área a aquisição de experiências em campo que lhe serão de extrema utilidade no exercício profissional, quando a partir de uma situação real ele levanta problemas, planeja e executa cuidados através entrevistas e consultas de enfermagem. Na disciplina Enfermagem Materno-Infantil e de Saúde Pública, procurou-se fazer os alunos participarem dessa experiência na área materno-infantil, incluindo atividades educacionais, a fím de colocá-los em ação em tarefas de educação para a saúde de modo integrado, visando familiarizá-los com uma nova filosofia de trabalho. $O$ quadro de atividades, nos evidencia a crescente demanda no N.O.S. e esboçar das metas e objetivos do Projeto embora numa avaliação parcial.

\section{CONCLUSAO:}

Os autores concluem da necessidade efetiva de açōes sistematizadas de enfermagem, de modo a planejar, executar e avaliar a Educação para Saúde Materno-Infantil, a nível individual, família e integração comunitária, acrescendo ainda que o enfermeiro terá que assumir as suas funçōes estando sempre presente aos níveis de prevenção.

A amostragem de visitas recebidas no "N.O.S.", entendimentos novos efetivados, o quadro estatístico evidenciado a crescente demanda para consultas de enfermagem, vem nos posicionando numa situação de realce no Sistema Institucional, de real significação e imperativa para a dinâmica dos Ambulatórios, permitindo-os visualizar o crescimento progressivo do Núcleo de Orientação à Saúde, "N.O.S." e o nascimento embrionário do Modelo proposto.

$O$ projeto em causa inclui entre seus propósitos a contribuição no sentido de 
PAIM, R.C.N. e colaboradoras - A disciplina enfermagem materno-infantil num programa de assistência integrada - "ensino, pesquisa e extensão. Rev. Bras. Enf:; DF, 31 : 417-442, 1978.

incutir uma nova mentalidade na equipe hospitalar, que se encontra em situação de maior favorabilidade em relação ao pessoal de medicina preventiva no que se refere ao acatamento pela clientela, de vez que a demanda de seus serviços ocorre sobretudo em momentos de grandes necessidades, fator assaz predisponente no sentido da aceitação de suas recomendaçōes. Se estabelecermos uma analogia, podemos sem dúvida afirmar que, enquanto o pessoal da medicina preventiva procura "vender", em relação à medicina preventiva, é a própria clientela que deseja "comprar". Com isso promover-se-á pari-passu meios eficazes de preservação e restauração da saúde mediante integração e participação comunitária. Com isto as internaçōes, passíveis de serem evitadas ou grandemente diminuída sua incidência, não seriam o fator impediente de uma melhor destinação de leitos.

Pelo fato de não ser mais aceitável o estabelecimento de compartimentos estanques, por não ser possível uma nítida linha divisória entre os procedimentos preventivos e curativos, avultase a necessidade de enfatização, em todas as oportunidades, da conveniência de uma maior participação do pessoal hospitalar nas tarefas de orientação à saúde.

Coerente com o propósito geral do Programa:

'Melhoria da saúde das mães e crianças da área, contribuindo para elevação do nível de vida do grupo familiar".
Sugerimos pois que:

- os enfermeiros passem a assumir seus papéis, junto a equipe iniciar um trabalho de Comunidade, mesma a partir de mínimos recursos no sentido de Educar para Saúde, essencialmente na clientela Materno-Infantil;

- atuem como Agente de Mudanças posicionando-se frente a uma realidade sócio somática de mesmos pais, assumindo suas funçōes como eminente educador;

- estabeleçam o sistema de integração em diferentes níveis nas açōes de enfermagem, visando uma assistência materno-infantil mais qualificada no sentido OBJETIVO maior do Sistema Nacional de Saúde - "O BEM ESTAR SOCIAL".

- que envolvam o hospital e a Comunidade num trabalho de participação autêntica, com vistas a melhoria do padrão de Educação para Saúde da população com reflexos na qualidade assistencial da clientela, uma performance do futuro profissional condizente com a realidade brasileira.

- que tais ações se efetuem com ênfase em vários níveis de complexidade crescente (nível puerpéreo áporo e de assistência terciária), com ênfase em aspectos preventivos.

- que haja, continuidade da assistência materno-infantil, melhora da qualidade de serviço e racionalização de recursos. 

ma de assistência integrada - "ensino, pesquisa e extensão. Rev. Bras. E ; DF, 31 : 417-442, 1978.

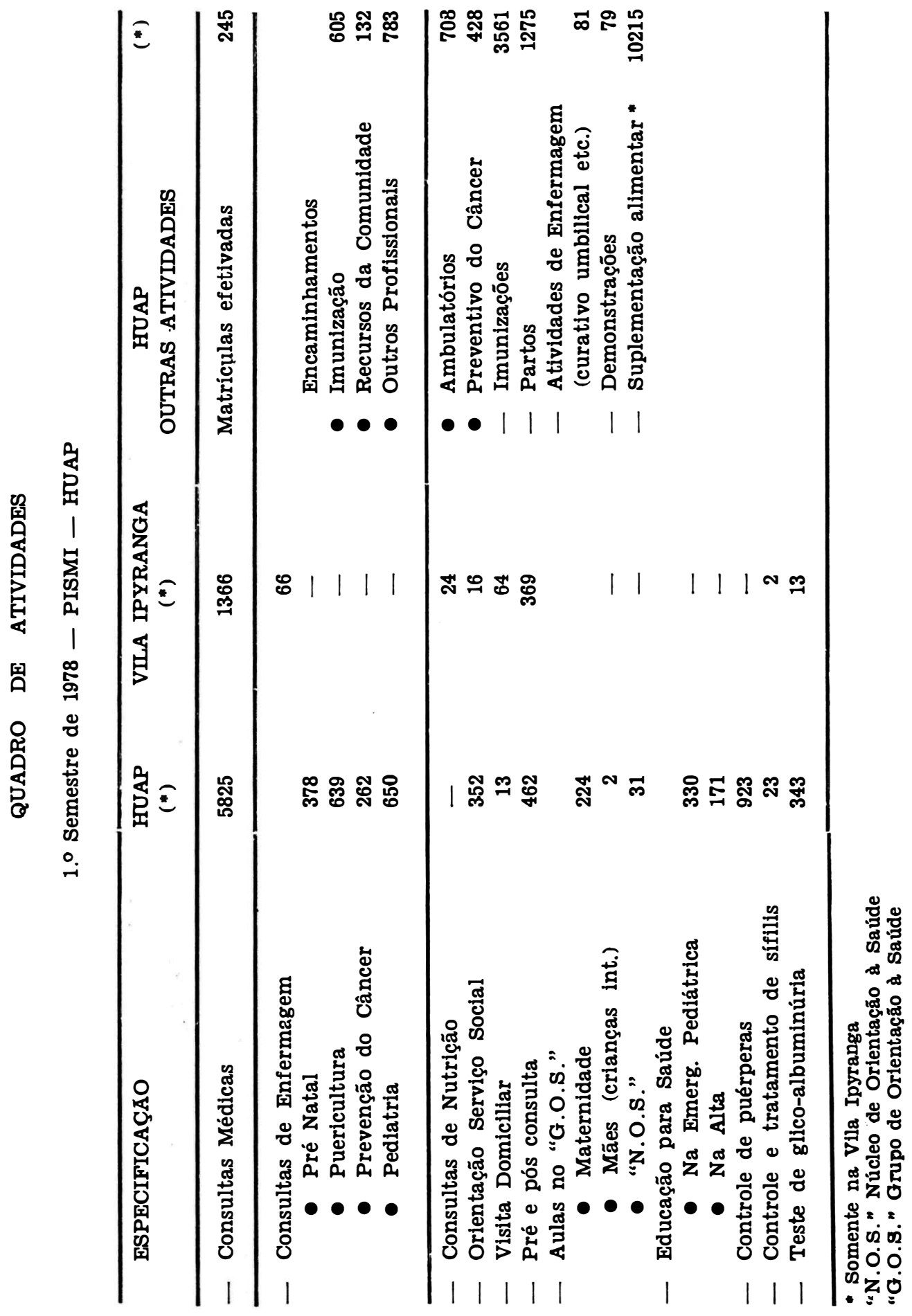


PAIM, R.C.N. e colaboradoras - A disciplina enfermagem materno-infantil num programa de assistência integrada - "ensino, pesquisa e extensâo. Rev. Bras. Ene.; DF, 31 : 417-442, 1978.

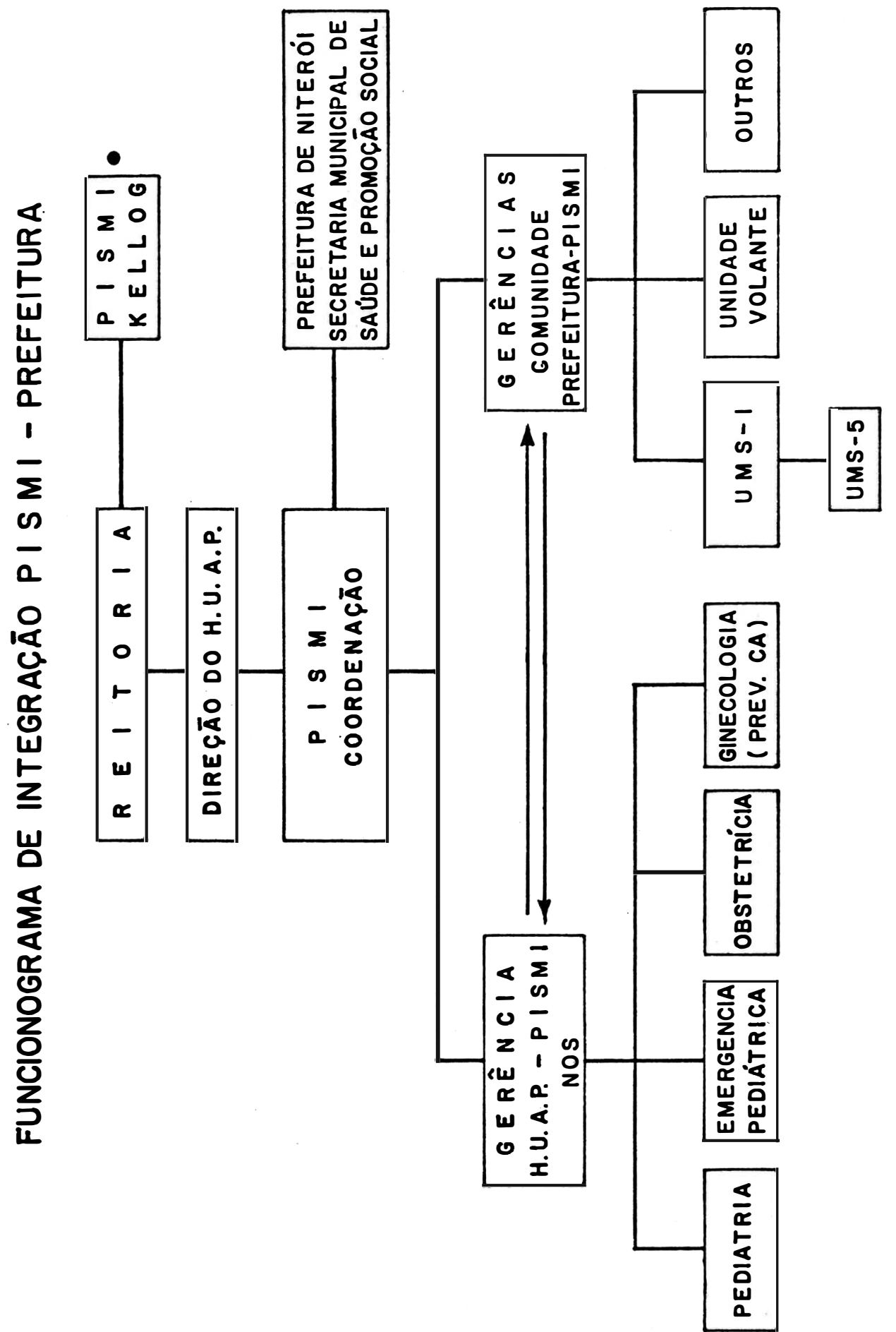


PADM, R.C.N. e colaboradoras - A disciplina enfermagem materno-infantil num programa de assistência integrada - "ensino, pesquisa e extensāo. Rev. Bras. Enf.; DF, 31 : 417-442, 1978.
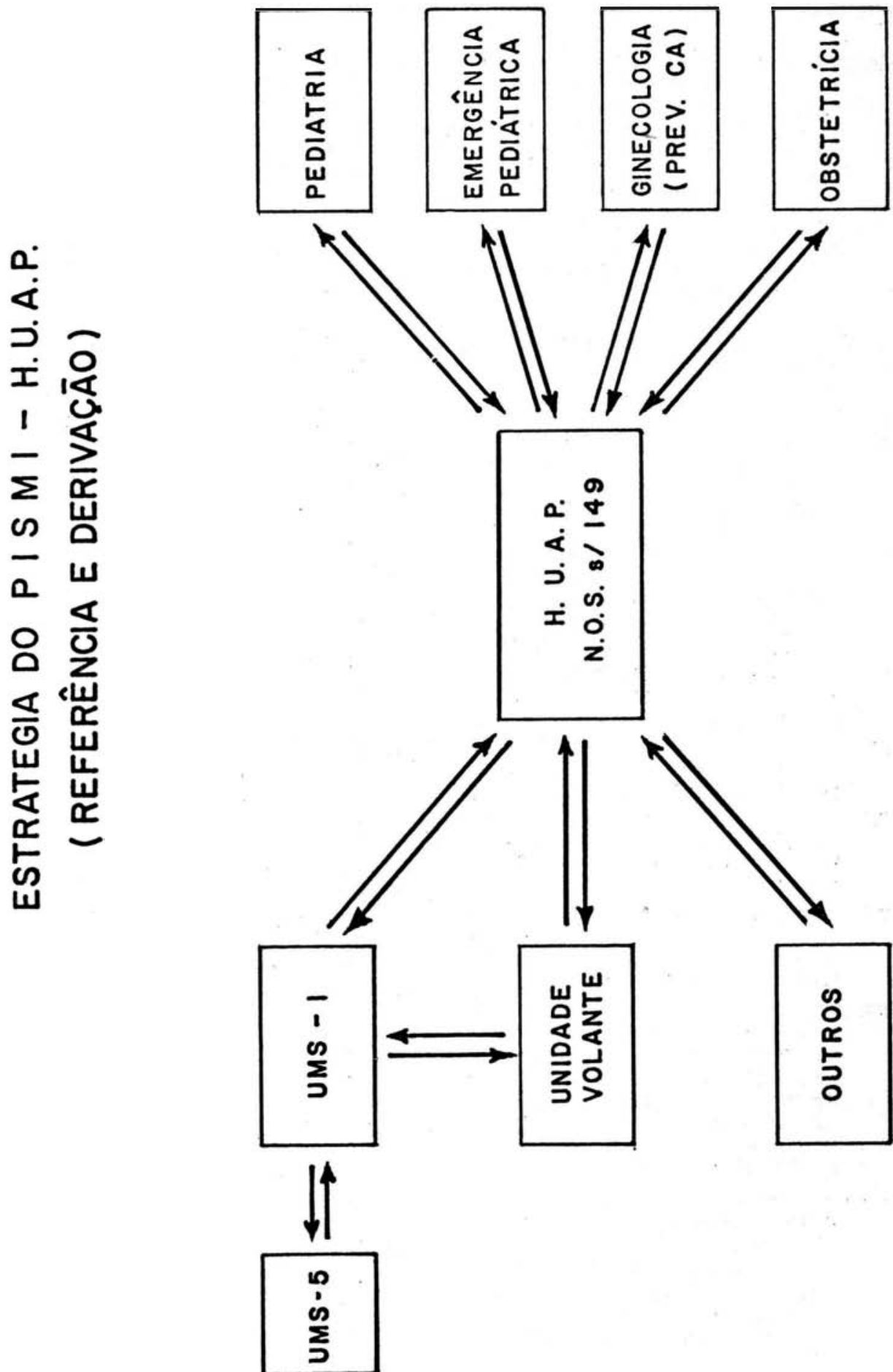
PAIM, R.C.N. e colaboradoras - A disciplina enfermagem materno-infantil num programa de assisténcia integrada - "ensino, pesquisa e extensão. Rev. Bras. Enf.; DF, 31 : 417-442, 1978.

\section{BIBLIOGRAFIA}

- ANDRADE, M. N. de - Integração docente-assistencial em enfermagem "Projeto Vitória". Trabalho apresentado na VI Conferência PAN Americana de Educação Médica. XIV Congresso Brasileiro de Educação Médica. Rio de Janeiro, 1976.

- Anais do Seminário. O Ensino da Proteção d Saúde Materno-Infantil em Função das Necessidades da Comunidade. Associação Brasileira de Escolas Médicas, Salvador, Bahia, 1970.

- ANDREW, Dean C. \& WILEY, I. D. Administration and Organization of the Guidance Program. New York, Harper \& Brothers. Publishers, 1958.

- Anais de Seminário. O Ensino da Proteção d̀ Saúde Materno-Infantil em Função das Necessidades da Comunidade. Assoclação Brasileira de Escolas Médicas, Salvador, Bahia, 1970.

- BRASIL, Leis e Decretos - Dec. lei n. ${ }^{\circ} 53$ de 21-2-66. Dispōe sobre a Reforma Universit́́ria. "Lei número $6.229 \mathrm{de}$ 17-7-75. Dispōe sobre a Organização do Sistema Nacional de Saúde".

- BLOOM, J. et Alii - Problem oriented charting. Am. J. Nurs., 71(1) :21442148, Nov., 1971.

- BULLOUGH, B. \& BOULOUGI, V. I. The emergence of modern nursing. New York. Mc Mallan, 1964.

- BERTALANFFY, L. Von. - Teoria Geral dos Sistemas. Traduçăo de Francisco M. Guímarães. Petrópolis, Vozes, 1973, $351 \mathrm{p}$.

- BRANDAO, M. B. - Tentativas de Padronização dos Serviços de Higiene. Pré-Natal, em Golânia. Rev. Golânia Med. 13 (1/2) : 51-64. Jan./jul. 1967.

- CHAVE, M. N. - Regionalização docente-assistencial e niveis de abrangência. Trabalho apresentado em 26-8-75 no Seminário sobre Hospitais de Ensino" realizado no Hotel Sheraton, Rilo de Janeiro, e organizado pelo Programa Nacional de Treinamento de Executivos.

- - - Saúde e Sistemas. Rio de Janeiro. Fundação Getúlio Vargas, 1972. 212 p.

- COMTLE de Expertos de OPS/OMS Ensenanza de Enf. Materno-Infantil en las Escuelas de Enfermaria de America Latina, premier informe 1973.
- DAVID, A. - A cibernética e o homem. Univ. Moderna. Publicaçōes D. Quixote, Lisboa. Original: La cybernétique el l'humani. Ed. Original: Gallimard, Paris, 1970. Editions, Gallimard, 1970. Trad. de Antonio Reis. $211 \mathrm{p}$.

- DECHERT, C. R. - O impacto sociad da cibernética. Tradução de Adilson Al Kum Cunha. Gb. Ed. Bloch, Editores. $1970.183 \mathrm{p}$.

- DOURADO, H. G. - Funçōes do Enfermeiro - Revista Bras. de Enfermagem 1, 2 e 3: Editorial, Junho, 1968.

- - A equipe de enfermagem. Rev. Bras. de Enfermagem (1): 82-5, jan./março, 1974.

- - Abordagens novas na atenção de enfermagem entre os enfermeiros dos serviços e o ensino. Rev. Bras. de Enf. (1):64, Jan./março, 1976.

- KONOPKA, G. - Serviço Social de Grupo - Um processo de ajuda. Trad. de Evangelina Lemos, $3 .^{\mathrm{a}}$ ed. Rio de Janeiro. Zahar ed., 1974. $310 \mathrm{p}$.

- LMMA, L. C. - O estruturalismo de LéviStrauss. Petrópolis, Vozes, 2." ed., 1970, 222 p.

- MATOS, A. V. - Padrōes de atribuiçōes de Pessoal de Enfermagem - S. 1 , SCP, 1972.

- MARLART, V. - Enseñanza superior de enfermeria. Cronica de la OMS 27 (6) :263-266, 1973.

- MUNOZ, E. - Modelos utilizados no ensino da medicina preventivaa y social: Rev. Educación Medica y Salud 7 (2) :125-134, 1973.

- MACHADO, E. Política de Formação de Recursos humanos para o setor Saúde - Subsídios para uma Definição. Trabalho apresentado na $\mathbf{V}$ Conferência Nacional de Saúde. Em Brasilia, 1976.

- OLIVEIRA, M. I. R. de - A enfermeira como coordenadora da assistência ao paciente. Análise sociométrica maltirrelacional. Sáo Paulo, Editora, 1974. $86 \mathrm{p}$.

- Organização Panamericana de la Salud Comité de Experts de Ensino Materno-Infantil OPAS/OMS. Informe Enseñanza de Enfermeria MaternoInfantil en las escuelas de America Latina, 1973. 
PAIM, R.C.N. e colaboradoras - A disciplina enfermagem materno-infantil num programa de assistência integrada - "ensino, pesquisa e extensão. Rev. Bras. Enf.; DF, 31 : 417-442, 1978.

- Organizacion Panamericana de la Salud. Seminário sobre Enseffanza de Enfermeria a nível universitário. Informe Final. Educación Médica y la Salud. v. 7(2) :221-242.

- OPS/OMS. Seminário Regional sobre assistência Materno-Infantill no Paraná. Relatório de Enfermagem n. ${ }^{0}$ 12, 1969.

- ORGANIZACION MUNDIAL DE LA SALUD - Funcion de los hospitais em los programas de protecion la salud. Premier Informe del Comitê de Experts de Organizacion de la Assistência Médica, Série de Informes Tecnicos. n. 122 - Genebra, 1957.

- PETERSEN, D. - Medicina Comunitaria. Documento de trabajo del III Seminario de Educación Médica en el Ecuador. Cuenca, Ecuador, 1974.

- RODRIGUES, N. de L. - Responsabilidade da enfermagem na prestação de Serviços d Comunidade. Revista Brasileira de Enfermagem. 25(4):13 jul./set., 1972.

- REDENTOR, M. do Cristo - Atividades de Enfermagem de Saúde Priblica no Hospital. R. P. H. 10(6):41-45, junho, 1972.

- RIBEIRO, M. I. - Porque integrar Ensino e Serviço de Enfermagem nos Hospitais Universitários. Seminário sobre integração de Ensino e Serviço de Enfermagem em Hospitais Universitários - Salvador/Bahia. Pub. OPAS/OMS. 1969, p. e UF'B, 40-49.

- - Reforma Universitária e o Curso de Graduação para enfermeiros. 20 (4) :235-243, agosto, 1967.

- ROGERS, C. - Terapia centrada no paciente. Santos, Livraria Martins Edit. 1974. $525 \mathrm{p}$.

- RIBEIRO, C. M. de - Atividades de Enfermagem de $\mathbf{S}$. Pública no Hospital. R. P. H. 10(6):41-45, junho 1972.

- SILVA, M. J. N. D. - O ensino da assistência educativa de Enfermagem, Rev. Bras. de Enf. 15(1-2):14-23, jan./abr., 1972.

- TEIXEIRA, M. S. - Integração dos Aspectos Sociais e de Saude no Curriculo das Escolas de Enfermagem: Elementos Necessários. Rev. Bras. de Enf. 13(1) :78-89, março, 1960. 
PAIM, R.C.N. e colaboradoras - A disciplina enfermagem materno-infantil num programa de assisténcia integrada - "ensino, pesquisa e extensåo. Rev. Bras. Enf.; DF, 31 : 417-442, 1978.

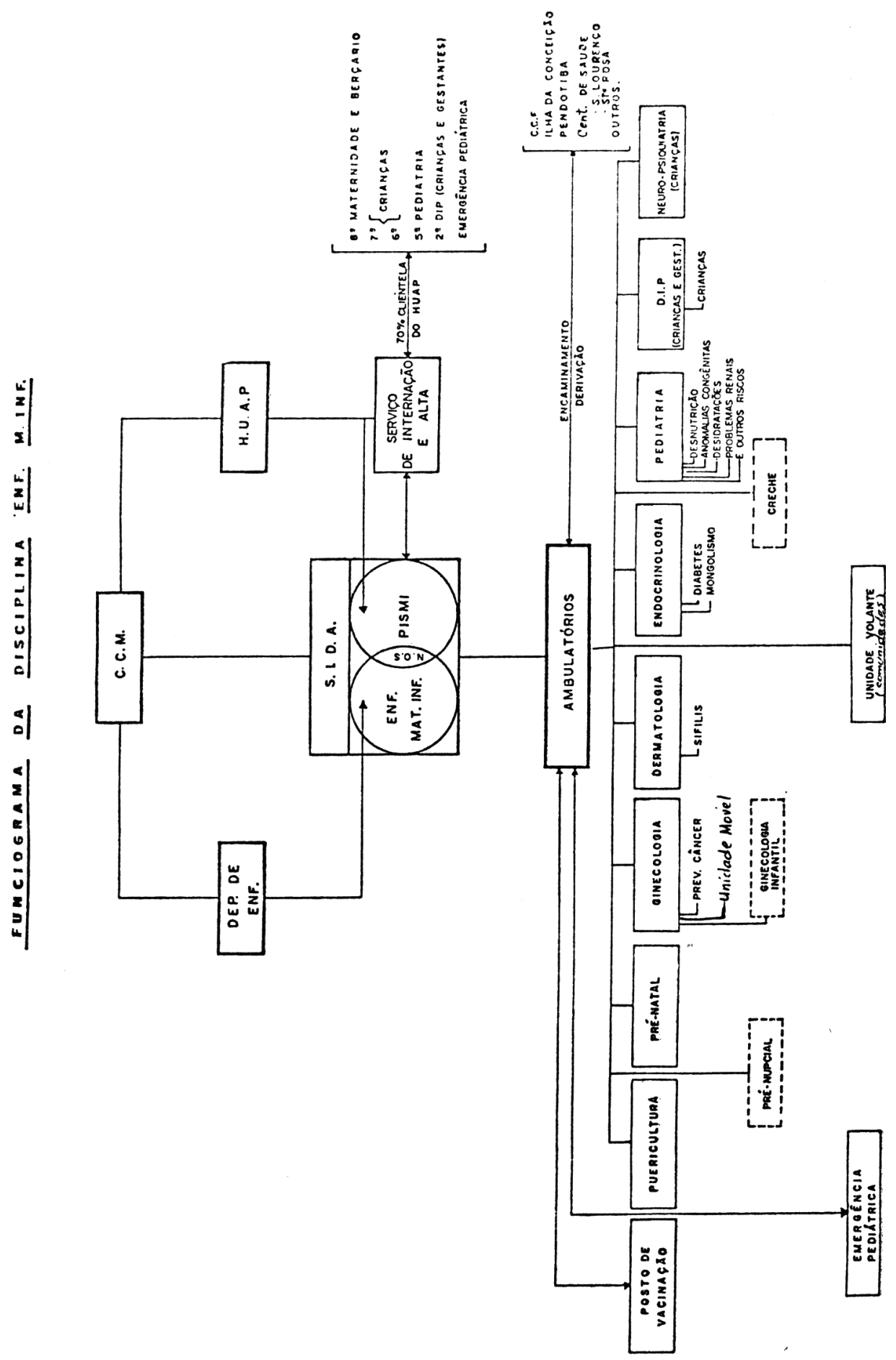


PAIM, R.C.N. e colaboradoras - A disciplina enfermagem materno-infantil num programa de assistência integrada - "ensino, pesquisa e extensāo. Rev. Bras. En?.; DF, 31 : 417-442, 1978.

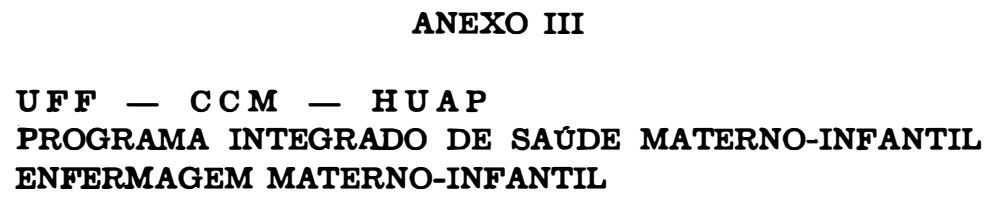

ANEXO III

UFF- CCM - HUAP

PROGRAMA INTEGRADO DE SAÚDE MATERNO-INFANTIL ENFERMAGEM MATERNO-INFANTIL

FICHA DE ALTA

EQUIPE MULTIPROFISSIONAL

AS. DA ENF.

DATA

ORIGEM:

I - Identificaçāo

Prontuário:

Nome:

Responsáveis:

Data de Nasc.:

Residência:

Diagnóstico:

Condiçōes de alta:

Retorno ambulatorial:

Médico responsável:

II - Dados da entrevista de enfermagem

1. Doenças que já teve
$\square$ Sarampo
$\square$ Coqueluche
Outras

2. Alergia a:

3. Imunizaçōes feitas:
$\square$ DPT
$\square$ DT
Sabin
$\square$ Meningite
VAV
Sarampo
BCG Oral
$\square$ Intradérmico

Reforço:

Outras vacinas:

Observaçōes:

4. Problemas de saúde identificados na família: (higiene pessoal, alimentaçōes, habitaçāo) 
PADM, R.C.N. e colaboradoras - A disciplina enfermagem materno-infantil num programa de assistência integrada - "ensino, pesquisa e extensāo. Rev. Bras. Enf.; DF, 31 : 417-442, 1978.

Comunicantes:

Foco:

Outras observaçōes:

III - Orientação à saúde

1. Prescriçāo médica

2. Consulta de enfermagem (níveis de aplicação de saúde)

- Relativo à criação (recuperação da doença, medidas de proteção e medicamentos prescritos).

- Relativo aos familiares (imunizaçōes e outras medidas profiláticas)

- Encaminhamentos: Imunizaçōes: Outros:

Ambulatório

Outros recursos da comunidade

- Seguimento do caso: Ambulatório de

Necessita visita domiciliar

Consulta de enfermagem

Aula de Orientação à Saúde

3 - Consulta de nutrição

4 - Orientação social

COMPAREÇA AO POSTO DE IMUNIZAÇAO

Atenção: 1. Entregue aos pais a receita médica

2. Volante específ:co do caso de 
PADM, R.C.N. e colaboradoras - A disciplina enfermagem materno-infantil num programa de assistência integrada - "ensino, pesquisa e extensảo. Bev. Bras. Enf.; DF, 31 : 417-442, 1978.
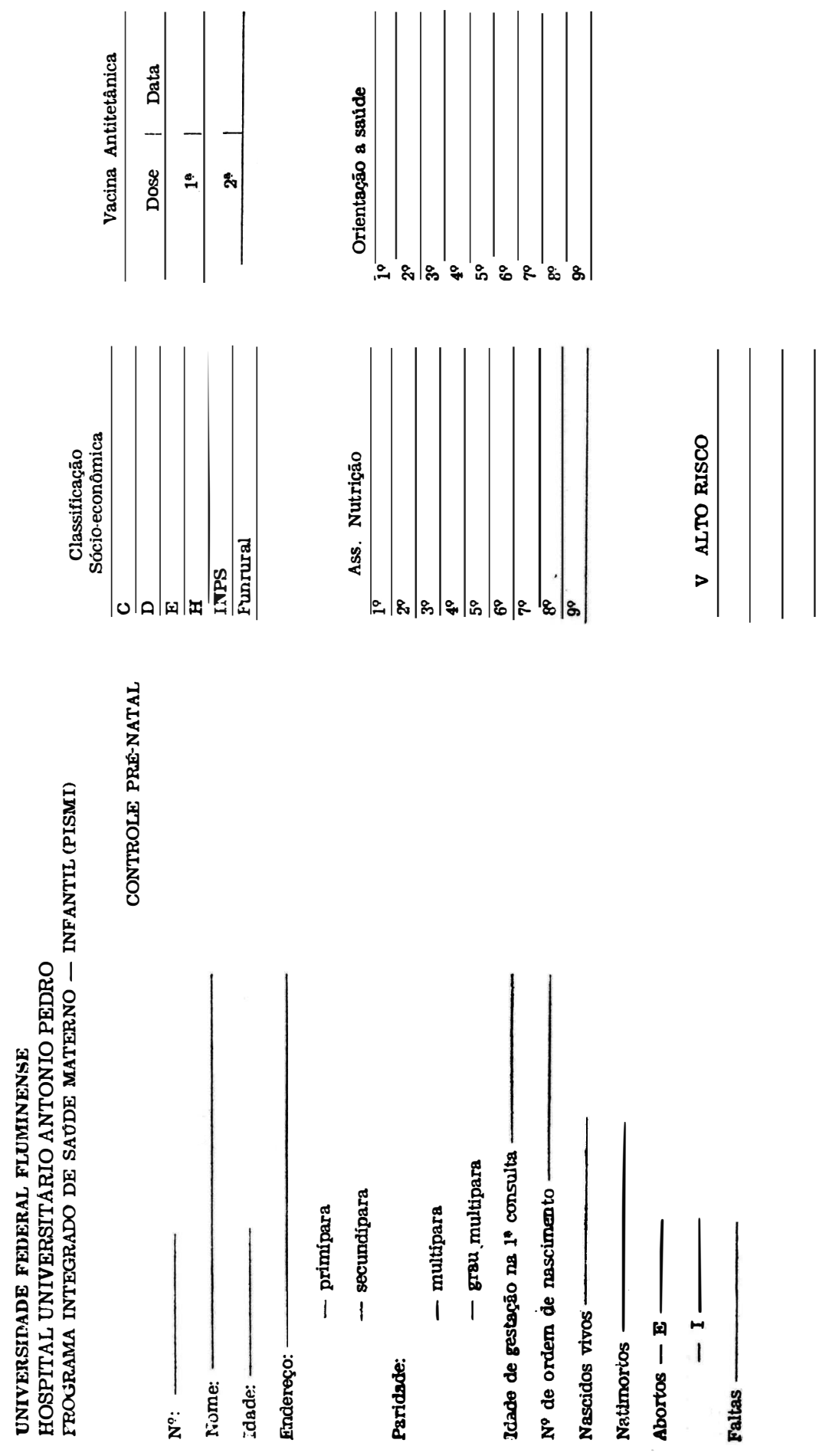
PAIM, R.C.N. e colaboradoras - A disciplina enfermagem materno-infantil num programa de assistência integrada - "ensino, pesquisa e extensāo. Rev. Bras. Enf.; DF, 31 : 417-442, 1978.

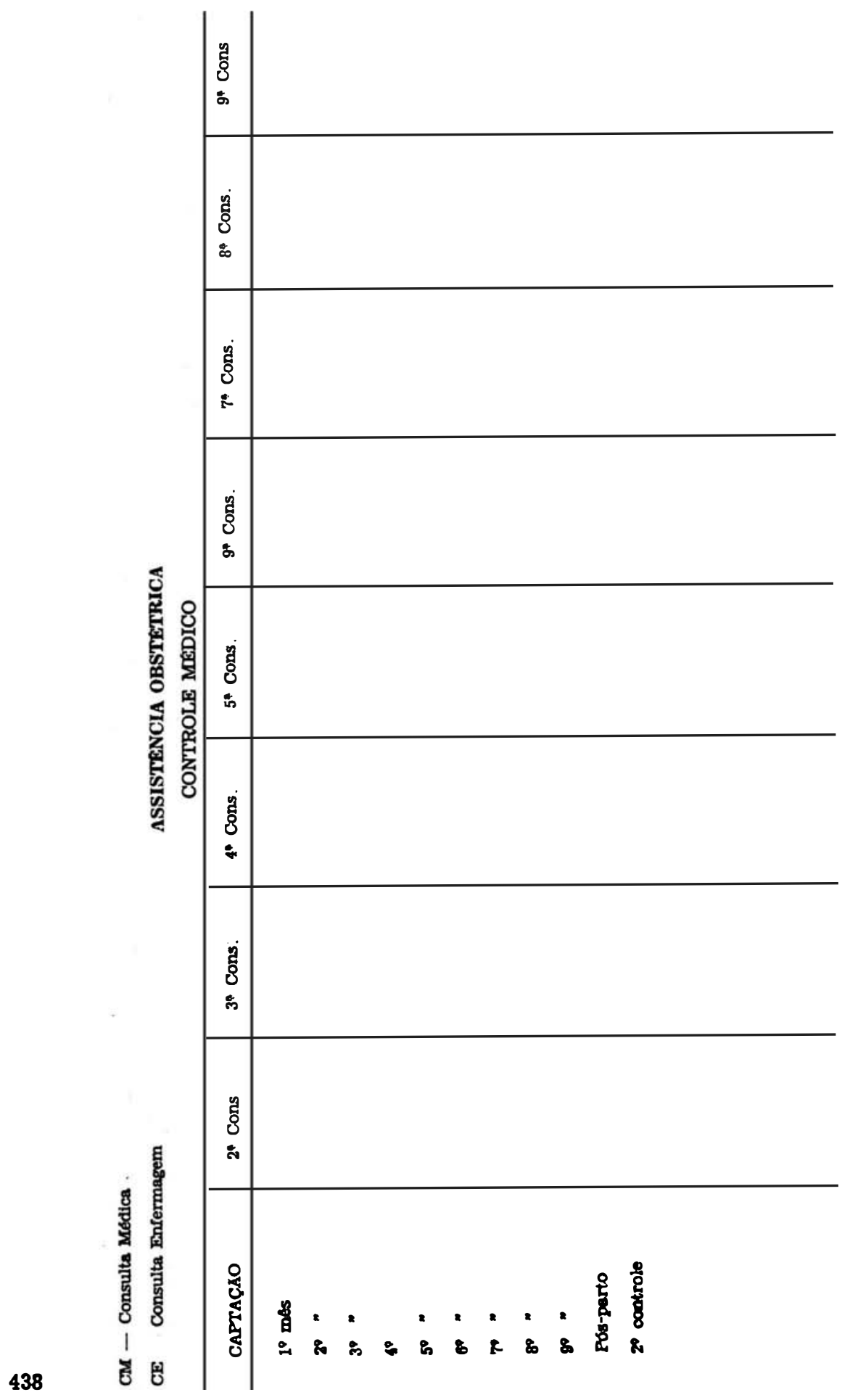


PAIM, R.C.N. e colaboradoras - A disciplina enfermagem materno-infantil num programa de assistência integrada - "ensino, pesquisa e extensāo. Rev. Bras. Enf.; DF, 31 : 417-442, 1978.

$\begin{array}{lr}\text { UFF - CCM } & \\ \text { HUAP - MATERNO INFANTIL - PISMI } & \text { A } \\ \text { PRONT.: } & 1 \\ & \text { PREV.: }\end{array}$

FICHA INTEGRADA VISITA DOMICILIAR DATA: ASSINATURA DOS PROFISSIONAIS $1-\ldots \ldots \ldots \ldots \ldots \ldots \ldots \ldots \ldots \ldots \ldots \ldots$

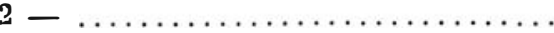$$
3
$$

I - IDENTIFICAÇAO:

NOME:

FILIAÇAO:

RESIDENCIA:

DIAGNOSTICO DE ENFERMAGEM:

DIAGNOSTICO MEDICO:

DATA DA HOSPITALIZAÇAO OU INICIO DO TRATAMENTO AMBULATORIAL:

CONDIÇOESS SÓCIO-ECONOMICO CULTURAIS:

CONDIÇOES DA HABITAÇAO:

II - COMPOSIÇAOO FAMILIAR:

\begin{tabular}{cccc}
\hline NOME & VINCULO & SITUAÇAO & ORIENTAÇAO AO GRUPO \\
& FAMILIAR & INDIVIDUAL & FAMILIAR
\end{tabular}

III - ENFERMAGEM

1 - Paciente

\begin{tabular}{lcc}
\hline PROBLEMAS IDENTIFICADOS & PERCEPCAO DO & PLANO \\
& ENFERMEIRO & TERAPEUTICO \\
\hline
\end{tabular}



PAIM, R.C.N. e colaboradoras - A disciplina enfermagem materno-infantil num progra- ma de assistência integrada - "ensino, pesquisa e extensảo. Rev. Bras. Enf.; DF, 31 : 417-442, 1978.

$$
\text { IV - SERVIÇO SOCIAL }
$$

\begin{tabular}{lll}
\hline DiagNóstico social & Plano dE TRATAMENTO OBSERVAÇOES
\end{tabular}

\begin{tabular}{lll} 
V - NUTRIÇAO & & \\
\hline AVALIAÇAO NUTRICIONAL & ORIENTAÇAOO & OBSERVAÇAO \\
\hline
\end{tabular}

$$
\text { VI - EVOLUÇAO DO CASO }
$$


PADM, R.C.N. e colaboradoras - A disciplina enfermagem materno-infantil num programa de assistência integrada - "ensino, pesquisa e extensāo. Rev. Bras. Enf.; DF, 31 : 417-442, 1978.

MEC - UFF - CCM

HOSPITAL UNIVERCITARIO ANTONIO PEDRO

PROGRAMA INTEGRADO DE SAUUDE MATERNO-INFANTIL - (PISMI)

Nome

Encaminhado a

Data Assinatura

Observação: Caso não seja incluída no Programa desta entidade, solicitamos devolução deste com a explicitação do motivo.

Assinatura:

Carimbo da entidade:

REFERENCIA E DERIVAÇAOO DE CASOS - COMUNIDADE - HUAP (N.O.S.) 1978 - 5 meses

Referência Da Comunidade para o N.O.S.

Especificaçāo

Vila Pendo- Ilha Unidade

meses

Ipiranga Cubango tiba Conceição Volante Outros Total

\begin{tabular}{llllllll}
\hline Março a Julho & 47 & 38 & 18 & 7 & 2 & 9 & 121 \\
\hline Sub-Total & 47 & 38 & 18 & 7 & 2 & 9 & 121 \\
\hline
\end{tabular}

DO N.O.S. PARA COMUNIDADE Sub Total 265 
PAIM, R.C.N. e colaboradoras - A disciplina enfermagem materno-infantil num programa de assistência integrada - "ensino, pesquisa e extensão. Rev. Bras. Enf.; DF, 31 : 417-442, 1978.

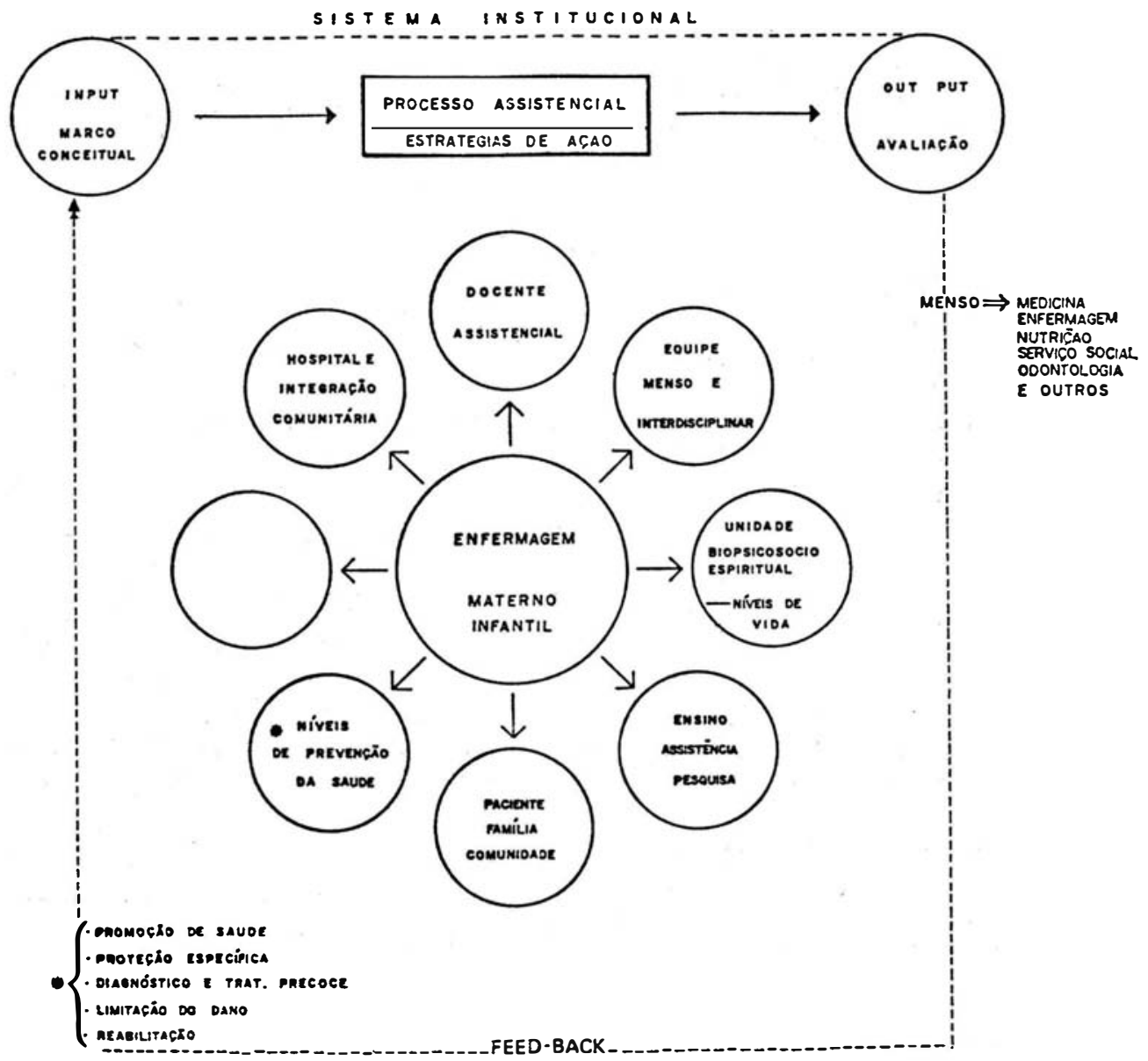

